\title{
Magnetic Resonance Imaging - Key to Understanding and Monitoring Disease Progression in Spondyloarthritis?
}
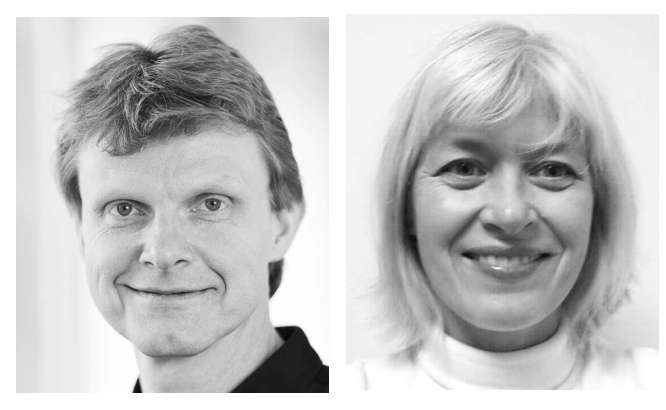

Understanding the process of structural progression in axial spondyloarthritis (axSpA) and elucidating the link/dissociation between inflammation and damage have attracted much attention, as has the question of whether avoiding structural progression is therapeutically possible. The impressive effect of tumor necrosis factor (TNF) inhibitors on disease activity without any apparent effect on structural damage progression as assessed by the standard measure (radiography) has fueled this interest ${ }^{1,2}$. Is the link between inflammation and damage nonexistent? Is it time-dependent (only occurring at a specific timepoint, e.g., early in the disease or only after long-lasting therapy)? Or is the apparent lack of a link the result of inadequate methods for measuring progression?

A sufficiently sensitive and reliable method for demonstrating change is a prerequisite to study structural progression. Preferably, different aspects of progression should be measurable, particularly if there is an interest in understanding details of the disease process. In this issue of The Journal, Maksymowych, et al describe the development and validation of a magnetic resonance imaging (MRI) scoring method for several aspects of structural damage in the sacroiliac joints $(\mathrm{SIJ})^{3}$. This is an important step in clarification of the development of these structural changes. Building on definitions of individual SIJ pathologies (erosion, backfill, fat infiltration, ankylosis) described in the MORPHO study by Weber, et al ${ }^{4,5}$, Maksymowych, et al describe and apply a newly developed scoring system by which the presence/absence of lesions is systematically scored in SIJ quadrants (fat, erosion) or halves (backfill, ankylosis) separately in each of 5 consecutive semicoronal slices through the cartilaginous part of the joint ${ }^{3}$. The quadratic per-slice scoring system follows the same principles as the Spondyloarthritis Research Consortium of Canada (SPARCC) scoring method for SIJ inflammation ${ }^{6}$. The structural damage scoring system is named "SPARCC sacroiliac joint structural score (SSS)" ${ }^{\prime 3}$. The SSS is described in detail and the interreader reliability determined. It demonstrated overall moderate to good reliability for both status scores and change scores over 1-2 years of followup ${ }^{3}$. Further validation in additional longitudinal cohorts with different disease durations, degrees of inflammation and damage, and therapeutic regimens are obviously needed.

MRI scoring systems for structural damage assessment in the SIJ have been published. However, these have generally focused on global assessment either of the joint or of joint quadrants as a whole 7,8 , not on separate scoring of individual slices. The new SSS method ${ }^{3}$ potentially provides a higher sensitivity to change and additionally allows a detailed assessment of the temporal and spatial relation between the individual pathologies. The system has already been used to demonstrate that backfill and fat infiltration are predictors of development of ankylosis ${ }^{9}$ and that TNF-inhibitor therapy is an independent predictor of resolution of erosion ${ }^{10}$ and development of ankylosis $^{11}$.

Spine involvement is another essential part of axSpA. Also in the spine, the level of detail in the proposed MRI assessment systems has varied markedly. Most scoring systems have provided a "global" score of each discovertebral unit (DVU) ${ }^{12,13}$, whereas more recently the Canada-Denmark method, in addition to providing detailed definitions of inflammatory and structural pathologies ${ }^{14,15}$, also defined a number of distinct anatomical locations (e.g., anterior and posterior corners of the vertebrae and the facet joints) of each DVU, where these pathologies could be evaluated ${ }^{16,17}$. Subsequently, the assessment of the structural components has been developed into scoring systems of fat (The Fat Spondyloarthritis Spine Score) ${ }^{18}$ and bone proliferation ${ }^{19}$. The approach of assessment of specific anatomical sites has been used for studying the relation

See Validation of the SPARCC MRI score in the SIJ, page 79

Personal non-commercial use only. The Journal of Rheumatology Copyright @ 2015 . All rights reserved. 
between inflammation and the development of radiographic syndesmophytes, i.e, new bone formation. Several studies have documented an association between the presence of bone marrow edema at the anterior corners of the vertebrae on MRI and subsequent development of syndesmophytes on radiography after 2 years of followup ${ }^{18,19,20}$. Presence as opposed to absence of MRI inflammation in the anterior vertebral corners resulted in 3 to 5 times increased risks for development of a new anterior radiographic syndesmophyte at that level ${ }^{18,19,20}$. In 3 studies, it was documented that radiographic syndesmophytes particularly occurred in the vertebral corners in which the inflammation had resolved following institution of anti-TNF therapy. This may be explained by TNF restricting new bone formation in an active inflammatory lesion, whereas inhibition of TNF (by applying a TNF-antagonist) allows tissue repair to manifest as new bone formation $19,20,21$. One study that used assessment per whole DVU has also documented that presence (as opposed to absence) of vertebral body inflammation is linked to development of new radiographic syndesmophytes, but the relation using this "per DVU approach" was only relatively weak (OR 1.66$)^{22}$. It is not surprising that it dilutes the effect of the link to assess the whole vertebral body (and not only the anatomical areas, i.e., anterior vertebral corners, in which the radiographic method allows visualization of syndesmophytes), and the weaker correlation illustrates the advantage of using more anatomically detailed methods when the pathogenic processes such as the inflammation-damage link are studied. It also indirectly encourages studies using the new "slicewise" SPARCC structural damage assessment method in a detailed location-by-location and slice-by-slice fashion: This will allow taking full advantage of the very large potential MRI gives to longitudinally and noninvasively study pathophysiologic processes in humans.

It should, however, be noted that syndesmophytes often develop in areas where inflammation has not been previously detected by MRI. This may be caused by inflammation being present at another timepoint than when MRI was performed, or by MRI not being sufficiently sensitive to document all inflamed areas, as documented by Gong, et $a l^{23}$, and/or by syndesmophytes developing without previous inflammation. Nevertheless, the fact that other studies have documented the relation between resolving inflammation and development of $\mathrm{fat}^{7}$ and between fat infiltration at the anterior corners of the vertebral bodies and subsequent development of radiographic syndesmophytes ${ }^{24}$ during anti-TNF therapy, strengthens the evidence behind a relation between resolution of inflammation and progression of damage.

Although the earliest studies unanimously reported the opposite ${ }^{25,26,27}$, recent data suggest that anti-TNF therapy may reduce radiographic progression. Baraliakos, et al analyzed the longterm effects of anti-TNF therapy by studying new bone formation by radiography over 8 years in patients with ankylosing spondylitis (AS), compared to a historical cohort that did not receive TNF blockers ${ }^{28}$. The radiographic progression rate was similar in the first 4 years, whereas in the last 4 years (years 4-8) the progression in the anti-TNF group was least pronounced ${ }^{28}$. This may be explained by the fact that even though new bone formation may be the immediate effect of resolution of inflammation by anti-TNF therapy ${ }^{18,19,20}$, new inflammatory lesions are prevented by continuous anti-TNF therapy, and thereby the bone formation induced by "anti-TNF-induced resolution of inflammation" will not continue ${ }^{29}$. Further, in recent multivariate analyses of 334 patients with AS, Haroon, et $a l^{29 a}$ found that TNF-inhibitor treatment was independently associated with a reduced radiographic progression; the $\mathrm{OR}$ of radiographic progression was $0.52(95 \% \mathrm{Cl}$ $0.30-0.88, \mathrm{p}<0.02$ ) with anti-TNF therapy as compared with nonsteroidal antiinflammatory drug therapy. These recent data contradict several studies that reported no effect of anti-TNF on structural progression, despite marked antiinflammatory effect. Detailed MRI methods will be helpful in further clarifying this issue and the processes behind it.

An interesting future question is how drugs with different modes of action [e.g., interleukin 23 (IL-23) or IL-17 inhibitors] will influence the processes of inflammation and damage. Potentially, the relationship between inflammation and damage may vary in response to inhibition of different pathways, as may the relative therapeutic response of entheseal versus discovertebral versus diarthrodial joint changes. Detailed MRI assessment systems will be very helpful for studying this. Whole-body MRI may further allow obtaining information on and differentiation between the effects of drugs with different modes of action, made possible by a detailed evaluation of not only axial but also peripheral joints and entheses in 1 examination $^{30}$.

Longterm followup studies with repeated MRI and radiography are needed to clarify whether remitting-relapsing disease activity causes structural damage progression in patients with axSpA, and whether continuous MRI remission is feasible and is followed by absence of structural progression. Such knowledge will help us decide whether MRI should be incorporated in future remission criteria and whether MRI remission (or other MRI criteria) should be the goal in future treat-to-target strategies.

The development and validation of novel MRI instruments to measure change in components of structural damage in $\mathrm{SpA}$, as described by Maksymowych, et $a l^{3}$, are important steps toward allowing us to fully understand and in detail follow the course of the disease during various treatments. They are also necessary to reveal the anatomical and temporal link or dissociation between inflammation and damage in SpA.

Personal non-commercial use only. The Journal of Rheumatology Copyright @ $\subset$ 2015. All rights reserved. 
MIKKEL ØSTERGAARD, MD, PhD, DMSc,

Professor of Rheumatology,

INGE J. SØRENSEN, MD, $\mathrm{PhD}$,

Consultant and Senior Lecturer of Rheumatology,

Copenhagen Center for Arthritis Research,

Center for Rheumatology and Spine Diseases,

Glostrup Hospital and Department of Clinical Medicine,

University of Copenhagen,

Copenhagen, Denmark.

Address correspondence to Prof. M. Østergaard, Copenhagen Center for Arthritis Research, Center for Rheumatology and Spine Diseases, Copenhagen University Hospital Glostrup, Nordre Ringvej 57, DK-2600 Glostrup, Denmark; E-mail: mo@dadlnet.dk

\section{REFERENCES}

1. Sieper J, Appel H, Braun J, Rudwaleit M. Critical appraisal of assessment of structural damage in ankylosing spondylitis: implications for treatment outcomes. Arthritis Rheum 2008; 58:649-56.

2. Maksymowych WP, Morency N, Conner-Spady B, Lambert RG. Suppression of inflammation and effects on new bone formation in ankylosing spondylitis: evidence for a window of opportunity in disease modification. Ann Rheum Dis 2013;72:23-8.

3. Maksymowych WP, Wichuk S, Chiowchanwisawakit P, Lambert R, Pedersen SJ. Development and preliminary validation of the Spondyloarthritis Research Consortium of Canada MRI sacroiliac joint structural score. J Rheumatol 2015;42:79-86.

4. Weber U, Lambert RG, Pedersen SJ, Hodler J, Østergaard M, Maksymowych WP. Assessment of structural lesions in sacroiliac joints enhances diagnostic utility of magnetic resonance imaging in early spondylarthritis. Arthritis Care Res 2010;62:1763-71.

5. Weber U, Pedersen SJ, Ostergaard M, Rufibach K, Lambert RG, Maksymowych WP. Can erosions on MRI of the sacroiliac joints be reliably detected in patients with ankylosing spondylitis? - A cross-sectional study. Arthritis Res Ther 2012;14:R124.

6. Maksymowych WP, Inman RD, Salonen D, Dhillon SS, Williams M, Stone M, et al. Spondyloarthritis Research Consortium of Canada magnetic resonance imaging index for assessment of sacroiliac joint inflammation in ankylosing spondylitis. Arthritis Rheum 2005;53:703-9.

7. Song IH, Hermann KG, Haibel H, Althoff CE, Poddubnyy D, Listing J, et al. Relationship between active inflammatory lesions in the spine and sacroiliac joints and new development of chronic lesions on whole-body MRI in early axial spondyloarthritis: results of the ESTHER trial at week 48. Ann Rheum Dis 2011;70:1257-63.

8. Madsen KB, Jurik AG. Magnetic resonance imaging grading system for active and chronic spondylarthritis changes in the sacroiliac joint. Arthritis Care Res 2010;62:11-8.

9. Maksymowych WP, Wichuk S, Chiowchanwisawakit P, Lambert RG, Pedersen SJ. Fat metaplasia and backfill are key intermediaries in the development of sacroiliac joint ankylosis in patients with ankylosing spondylitis. Arthritis Rheumatol 2014;66:2958-67.

10. Pedersen SJ, Wichuk S, Chiowchanwisawakit P, Lambert RG, Maksymowych WP. Tumor necrosis factor inhibitor therapy but not standard therapy is associated with resolution of erosion in the sacroiliac joints of patients with axial spondyloarthritis. Arthritis Res Ther 2014;16:R100.

11. Pedersen SJ, Poddubnyy D, Sorensen IJ, Loft AG, Hindrup JS, Thamsborg G, et al. Inflammation and structural progression in the sacroiliac joints of patients with axial SpA treated with adalimumab or placebo as assessed by the Berlin and the Spondyloarthritis Research Consortium Of Canada MRI methods [abstract]. Arthritis Rheum 2014;65 Suppl:S1218.

12. Braun J, Baraliakos X, Golder W, Brandt J, Rudwaleit M, Listing J, et al. Magnetic resonance imaging examinations of the spine in patients with ankylosing spondylitis, before and after successful therapy with infliximab: evaluation of a new scoring system. Arthritis Rheum 2003;48:1126-36.

13. Madsen KB, Jurik AG. MRI grading method for active and chronic spinal changes in spondyloarthritis. Clin Radiol 2010;65:6-14.

14. Lambert RGW, Pedersen SJ, Maksymowych WP, Chiowchanwisawakit $\mathrm{P}$, Østergaard M. Active inflammatory lesions detected by magnetic resonance imaging in the spine of patients with spondyloarthritis - Definitions, assessment system and reference image set. J Rheumatol Suppl. 2009 Dec;84:3-17.

15. Østergaard M, Maksymowych WP, Pedersen SJ, Chiowchanwisawakit P, Lambert RGW. Structural lesions detected by magnetic resonance imaging in the spine of patients with spondyloarthritis - Definitions, assessment system, and reference image set. J Rheumatol Suppl. 2009 Dec;84:18-34.

16. Pedersen SJ, Zhao Z, Lambert RG, Wichuk S, Østergaard M, Weber U, et al. The FAt Spondyloarthritis Spine Score (FASSS): development and validation of a new scoring method for the evaluation of fat lesions in the spine of patients with axial spondyloarthritis. Arthritis Res Ther 2013;15:R216.

17. Pedersen SJ, Østergaard M, Lambert RGW, Maksymowych WP. MRI of the spine for detection of bone spurs and ankylosis in patients with ankylosing spondylitis: Does MRI offer any advantages over radiography? Arthritis Rheum 2014;2012:S251-2.

18. Baraliakos X, Listing J, Rudwaleit M, Sieper J, Braun J. The relationship between inflammation and new bone formation in patients with ankylosing spondylitis. Arthritis Res Ther 2008;10:R104.

19. Maksymowych WP, Chiowchanwisawakit P, Clare T, Pedersen SJ, Østergaard M, Lambert RG. Inflammatory lesions of the spine on magnetic resonance imaging predict the development of new syndesmophytes in ankylosing spondylitis: evidence of a relationship between inflammation and new bone formation. Arthritis Rheum 2009;60:93-102.

20. Pedersen SJ, Chiowchanwisawakit P, Lambert RG, Østergaard M, Maksymowych WP. Resolution of inflammation following treatment of ankylosing spondylitis is associated with new bone formation. J Rheumatol 2011;38:1349-54.

21. Baraliakos X, Heldmann F, Callhoff J, Listing J, Appelboom T, Brandt J, et al. Which spinal lesions are associated with new bone formation in patients with ankylosing spondylitis treated with anti-TNF agents? A long-term observational study using MRI and conventional radiography. Ann Rheum Dis 2014;73:1819-25.

22. van der Heijde D, Machado P, Braun J, Hermann KG, Baraliakos $\mathrm{X}, \mathrm{Hsu} \mathrm{B}$, et al. MRI inflammation at the vertebral unit only marginally predicts new syndesmophyte formation: a multilevel analysis in patients with ankylosing spondylitis. Ann Rheum Dis 2012;71:369-73.

23. Gong Y, Zheng N, Chen SB, Xiao ZY, Wu MY, Liu Y, et al. Ten years' experience with needle biopsy in the early diagnosis of sacroiliitis. Arthritis Rheum 2012;64:1399-406.

24. Chiowchanwisawakit P, Lambert RG, Conner-Spady B, Maksymowych WP. Focal fat lesions at vertebral corners on magnetic resonance imaging predict the development of new syndesmophytes in ankylosing spondylitis. Arthritis Rheum 2011;63:2215-25.

25. van der Heijde D, Landewe R, Baraliakos X, Houben H, van Tubergen A, Williamson $\mathrm{P}$, et al. Radiographic findings following two years of infliximab therapy in patients with ankylosing spondylitis. Arthritis Rheum 2008;58:3063-70.

26. van der Heijde D, Salonen D, Weissman BN, Landewe R, Maksymowych WP, Kupper H, et al. Assessment of radiographic progression in the spines of patients with ankylosing spondylitis treated with adalimumab for up to 2 years. Arthritis Res Ther

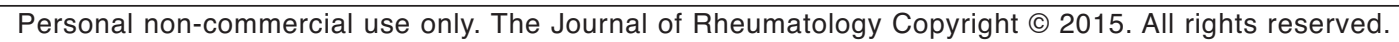


2009; 11:R127.

27. van der Heijde D, Landewe R, Einstein S, Ory P, Vosse D, Ni L, et al. Radiographic progression of ankylosing spondylitis after up to two years of treatment with etanercept. Arthritis Rheum 2008;58:1324-31.

28. Baraliakos X, Haibel H, Listing J, Sieper J, Braun J. Continuous long-term anti-TNF therapy does not lead to an increase in the rate of new bone formation over 8 years in patients with ankylosing spondylitis. Ann Rheum Dis 2014;73:710-5.

29. Maksymowych WP. Evidence in support of the validity of the TNF brake hypothesis. Ann Rheum Dis 2013;72:e31. 29a. Haroon N, Inman RD, Learch TJ, Weisman MH, Lee M, Rahbar $\mathrm{MH}$, et al. The impact of tumor necrosis factor $\alpha$ inhibitors on radiographic progression in ankylosing spondylitis. Arthritis Rheum 2013;65:2645-54.

30. Poggenborg RP, Eshed I, Ostergaard M, Sørensen IJ, Møller JM, Madsen OR, et al. Enthesitis in patients with psoriatic arthritis, axial spondyloarthritis and healthy subjects assessed by 'head-to-toe' whole-body MRI and clinical examination. Ann Rheum Dis 2014; Jan 3 (E-pub ahead of print).

J Rheumatol 2015;42:1-4; doi:10.3899/jrheum.141402 